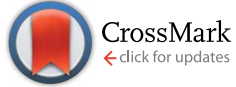

Cite this: RSC Adv., 2016, 6, 44993

DOI: 10.1039/c6ra90042a

www.rsc.org/advances

\title{
Correction: Structure of a thermostable methionine adenosyltransferase from Thermus thermophilus HB27 reveals a novel fold of the flexible loop
}

\author{
Yanhui Liu, Wenhe Wang, Weiwei Zhang, Yanan Dong, Fengjiao Han, Muslim Raza, \\ Luo Liu, Tianwei Tan* and Yue Feng*
}

Correction for 'Structure of a thermostable methionine adenosyltransferase from Thermus thermophilus HB27 reveals a novel fold of the flexible loop' by Yanhui Liu et al., RSC Adv., 2016, 6, 41743-41750.

An error was present in Fig. 2A of the published manuscript and the correct version of Fig. 2 is reproduced below. Correspondingly, the text in Section 3.1 of the manuscript should be modified (as shown in italics).

\subsection{Stability assay}

In our previous studies, a thermostable MAT was identified from Thermus thermophilus HB27 (TtMAT). ${ }^{16}$ To further characterize this enzyme and evaluate its application of biotechnological interest, we moved on to test whether TtMAT exhibits better thermostability than the well-studied EcMAT. We incubated TtMAT and EcMAT at 40, 60, and $80^{\circ} \mathrm{C}$ for 25 hours and tested the activity loss of both enzymes over time, at these three temperatures. The two enzymes did not show obvious activity difference during the incubation at $40^{\circ} \mathrm{C}$. At $60^{\circ} \mathrm{C}$, the activity of EcMAT underwent a quick decrease and dropped to almost $30 \%$ of the initial activity after 25 hours, whereas TtMAT showed even higher activity $\left(60^{\circ} \mathrm{C}\right)$ than the initial activity during the same time (Fig. 2B). A possible reason for the increased activity of TtMAT during incubation might be that since the optimal temperature for the growth of Thermus thermophilus $\mathrm{HB} 27$ ranges from $50{ }^{\circ} \mathrm{C}$ to $82{ }^{\circ} \mathrm{C}$, the TtMAT enzyme purified at low temperature $\left(4{ }^{\circ} \mathrm{C}\right)$ might need some incubation time at its optimal temperature to restore its maximal activity. During this incubation period, the conformational change of the enzyme might organize its active site and surrounding regions to a fully accessible state for the substrate, thus increasing the activity of the enzyme. At $80^{\circ} \mathrm{C}$, the activities of TtMAT and EcMAT dropped to zero in 15 and 5 hours, respectively (Fig. 2C). In all, our results at three different temperatures all suggested that TtMAT is more thermostable than EcMAT and might have a better application in biological industry. 


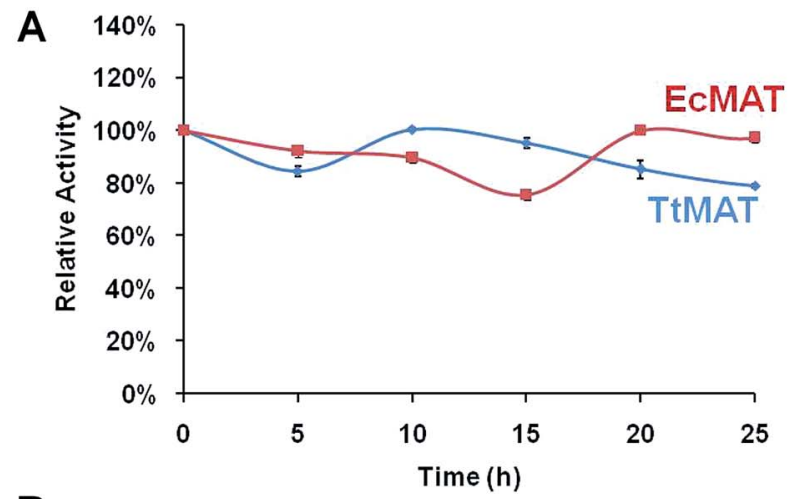

B
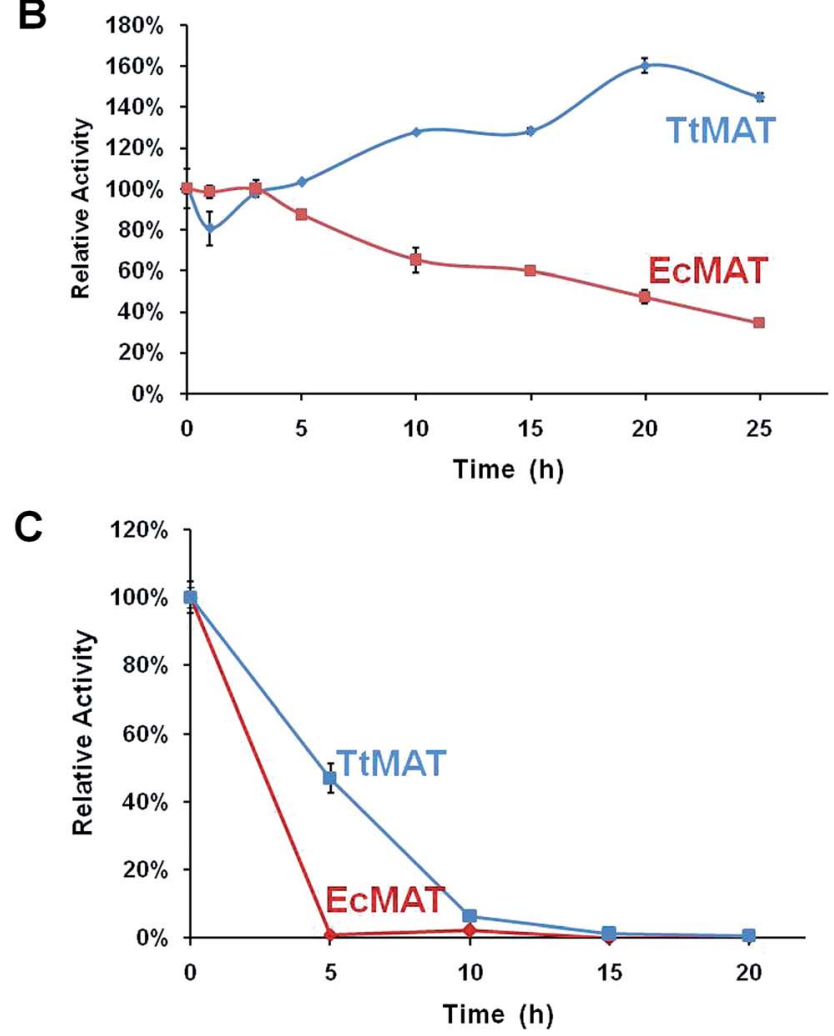

Fig. 2 TtMAT exhibits better thermostability than EcMAT. TtMAT and EcMAT enzyme were incubated in $40{ }^{\circ} \mathrm{C}(\mathrm{A}), 60^{\circ} \mathrm{C}(\mathrm{B})$, and $80{ }^{\circ} \mathrm{C}(\mathrm{C})$ for the indicated time. At scheduled time, $20 \mathrm{ml}$ of sample was analyzed for its enzyme activity as mentioned in the methods. The activity at 0 hour was defined as $100 \%$ for both enzymes.

The Royal Society of Chemistry apologises for these errors and any consequent inconvenience to authors and readers. 